\title{
Growth and development of pulmonary circulation in pulmonary atresia with ventricular septal defect and major aortopulmonary collateral arteries
}

\author{
SHEILA G HAWORTH, FERGUS J MACARTNEY \\ From the Department of Paediatric Cardiology, Institute of Child Health, Guilford Street, London
}

SUMMARY In 11 necropsy specimens of pulmonary atresia with ventricular septal defect and major aortopulmonary collateral arteries, central pulmonary arteries were present in all cases, supplied by collateral arteries which anastomosed with a lobar pulmonary artery or, less commonly, with a central pulmonary artery. These normally connected pulmonary arteries frequently perfused only a minority of bronchopulmonary segments. The remaining segments were connected to collateral arteries which, within the lung, were continuous with vessels which had the structure of normally connected vessels and branched with the pre- and intra-acinar airways in a normal manner to perfuse the alveolar capillary bed. These collateral arteries and the intrapulmonary vessels with which they anastomosed had no connection, either macroscopically or microscopically, with either the central pulmonary arteries or their branches within the lung. Irrespective of the type of proximal connection, the segmental pulmonary arteries were generally abnormally small. Stenoses occurred in 58.8 per cent of collateral arteries, usually as a thick-walled narrowed muscular section between the aorta and lung. Microscopically, quantitative morphometric analysis showed that within the respiratory unit the pulmonary circulation had failed to grow normally in all save the youngest patient dying at 12 days of age. The structural changes were usually consistent with a reduction in pulmonary blood flow; only three cases contained any segments of lung showing structural evidence of pulmonary hypertension. These anatomical and histological findings are discussed in relation to the embryology, nomenclature, and natural history of pulmonary atresia with ventricular septal defect and major aortopulmonary collateral arteries. The structural findings provide a rational basis for the clinical management of this condition.

The preoperative assessment of pulmonary atresia with ventricular septal defect and major aortopulmonary collateral arteries has been improved by selective catheterisation of the collateral arteries. Corrective surgery is now possible using valvebearing conduits to establish continuity between the right ventricle and pulmonary circulation. The management of this condition remains imperfect, however, mainly because the anatomy of the pulmonary circulation is poorly understood. Radiological, haemodynamic, and surgical studies often provide an incomplete picture of the source of pulmonary blood supply and the intrapulmonary arterial branching pattern. In addition, the structure of the pulmonary circulation at alveolar level determines pulmonary vascular resistance and

Received for publication 17.August 1979 hence prognosis, but its growth and development has not previously been studied in this condition.

In an attempt to provide a rational basis for treatment, the central pulmonary arteries and collateral arteries were traced from their origin to the lung periphery in 11 necropsy specimens. Peripheral lung structure was analysed using quantitative morphometric techniques.

\section{Subjects and methods}

The lungs of 11 patients who died between 1950 and 1978 were studied (Table 1). Cyanosis was noted within the first two days in four babies, within the first two months in a further four, at 5 months in case 7 , and at 2 years in the remaining documented case (one case was undocumented). Nine children underwent cardiac catheterisation. 
Table 1

\begin{tabular}{|c|c|c|c|c|c|c|c|c|}
\hline $\begin{array}{l}\text { Case } \\
\text { no. }\end{array}$ & Age at death & Sex & \multicolumn{2}{|c|}{$\begin{array}{l}\text { No. of collaterals } \\
\text { to each lung }\end{array}$} & \multicolumn{2}{|c|}{$\begin{array}{l}\text { Destination of } \\
\text { collaterals }\end{array}$} & \multicolumn{2}{|c|}{$\begin{array}{l}\text { No. bronchopulmonary } \\
\text { segments connected } \\
\text { to central } P A\end{array}$} \\
\hline 1 & 12 days & $\mathbf{M}$ & 2 & 1 & $\mathbf{R P A}+\mathbf{P}$ & $\mathbf{P}$ & 3 & 2 \\
\hline 2 & 15 days & $\mathbf{M}$ & 2 & 2 & $\mathbf{P}$ & $\mathbf{U L P A}+\mathbf{P}$ & 8 & 3 \\
\hline 3 & 1 month & $\mathrm{F}$ & 2 & 1 & $\mathbf{P}$ & LPA & 6 & 9 \\
\hline 5 & 3 months & $\mathrm{M}$ & 2 & 1 & $\mathbf{P}$ & LLPA & 4 & 9 \\
\hline 6 & 4 months & $\mathrm{F}$ & 3 & 2 & $\mathbf{P}$ & $\mathrm{ULPA}+\mathrm{P}$ & 1 & 3 \\
\hline 7 & 5 months & M & 4 & $\overline{1}$ & $\mathrm{ULPA}+\mathbf{P}$ & $\mathbf{P}$ & 1 & 3 \\
\hline 8 & 5 months & $\mathbf{F}$ & 3 & 0 & LLPA + P & - & 4 & 9 \\
\hline 9 & 5 months & $\mathbf{F}$ & 3 & 2 & $\mathbf{P}$ & LLPA + P & 6 & 3 \\
\hline 10 & 7 months & $\mathbf{F}$ & 2 & 3 & $\mathbf{U L P A}+\mathbf{P}$ & $\mathbf{P}$ & 8 & 0 \\
\hline 11 & 3 years & M & 3 & 3 & $\mathbf{U L P A}+\mathbf{P}$ & LLPA + P & 5 & 3 \\
\hline
\end{tabular}

PA, pulmonary artery; ULPA, upper lobe pulmonary artery; LLPA, lower lobe pulmonary artery; P, parenchyma supplied by collaterals not connected to central pulmonary arteries or their branches.

Central pulmonary arteries were demonstrated in six patients, but selective angiography of the collateral arteries was performed in only three patients, those admitted after 1976. Central pulmonary arteries were shown in all patients in whom selective injections were performed. Five patients did not receive surgical treatment. Three others died at or immediately after operation and are included in the untreated group. In the remaining three patients, an aortopulmonary anastomosis increased pulmonary blood flow in cases 4 and 8 , but an aortocollateral anastomosis did not increase flow in case 6.

\section{PATHOLOGICAL TECHNIQUES}

The diagnosis was confirmed at necropsy in all cases. Atrial situs was normal. In nine cases the lungs had been fixed in formalin, uninflated, for routine pathological study. In the other two specimens the pulmonary arterial circulation was injected with a "Micropaque" gelatin mixture and the lungs were fixed by inflating the airways with formol saline. ${ }^{2}$ In all 11 cases the bronchial branching pattern was traced from the hilum to segmental level and compared with the normal pattern. ${ }^{3}$ By dissection, the course of each pulmonary artery and collateral artery arising from the aorta was mapped out on a diagram illustrating the normal bronchial branching pattern (Fig. 1 and 2). The external diameter of all arteries was measured at intervals along the pathways. The collateral arteries, central pulmonary arteries, and all arteries within the lung down to subsegmental level were examined for localised stenoses and segmental narrowing. Because most of the specimens were small and fixed, the bronchial arteries (those vessels arising from the plexus around the lower end of the trachea and carina, and running along the wall of the bronchi) could only be identified with certainty in eight cases. Radiographs were taken of the two injected specimens.

\section{Microscopical studies}

In the two injected specimens, after tracing the intrapulmonary arterial branching pattern as far as possible macroscopically, blocks of tissue which contained vessels connecting with collateral arteries were serially sectioned. These vessels were then traced to the alveolar wall. In order to study peripheral pulmonary vascular structure, lung tissue was taken from the two injected and seven uninjected specimens. This gave a total of 33 blocks, in each of which the origin of the blood supply to the block had been traced macroscopically. Applying quantitative morphometric techniques, the muscularity, size, and number of intra-acinar* arteries was determined and the findings were compared with those in age-matched controls. ${ }^{45}$ In each case both injected and uninjected, percentage arterial wall thickness was calculated in a large proportion of vessels, for example 280 vessels in case 4 . In arteries cut transversely, the external diameter of an artery was measured across two diameters by taking the distance between external elastic laminae; wall thickness was measured from external to internal elastic lamina at the four sites where the measured diameters cut the wall and the mean of the four readings was used. The percentage medial wall thickness was then calculated as:

$$
\frac{2 \times \text { wall thickness }}{\text { external diameter }} \times 100
$$

In addition, in both injected and uninjected tissue extension of muscle into the acinus was determined. In the injected tissue, the external diameter of arteries accompanying terminal and respiratory bronchioli, alveolar ducts, and alveolar walls was * An acinus is all the lung tissue distal to a terminal bronchiolus. 
estimated, while in the uninjected tissue only the size of arteries accompanying the respiratory bronchioli, the most easily and accurately identifiable of the peripheral airways, was measured. Only in the injected specimens was the number of alveoli and arteries per unit area of lung, expressed as a ratio, obtained for each block of tissue.

Out of a total of 48 collateral arteries, transverse sections of 13 vessels were examined at their origin from the aorta, midway along their course, and where the collateral artery first came to lie adjacent to a main, lobar or segmental bronchus.

All the sections were stained with haematoxylin and eosin, and with Miller's elastic van Gieson stain.

\section{Results}

In all cases, the bronchial branching pattern was normal, central pulmonary arteries were present, and pulmonary venous return was normal. A right aortic arch was present in three cases.

\section{ORIGIN OF COLLATERAL ARTERIES FROM AORTA}

In each case either two or three collateral arteries arose in close proximity from the descending thoracic aorta, at the inferior margin of the left main brochus in the presence of a left aortic arch and immediately below and to the right of the carina in the presence of a right arch. Five collateral arteries branched 1 to $2 \mathrm{~cm}$ from their origin. Ultimately, a total of 39 collaterals from the descending aorta entered the lungs studied (Table 1). An additional six collaterals arose underneath the aortic arch. A further three vessels arose from a small artery running down the lateral margin of the trachea, whose origin could not be traced. Thus a total of 48 collateral arteries entered the lungs studied, the majority of which arose from the descending thoracic aorta.

\section{PULMONARY ARTERIAL BRANCHING PATTERN}

In any one case, a collateral artery might anastomose with either a central pulmonary artery, or a normally connected lobar pulmonary artery, or else enter the lung parenchyma and appear to branch within it, having no connection either with the central pulmonary arteries or with the vessels arising from them within the lung. All cases had more than one type of arterial connection and these could be found in any combination (Table 1, Fig. 1 and 2).

Collateral arteries destined to join an upper lobe pulmonary artery ran posterior to the main bronchus, anastomosing at its superior margin with

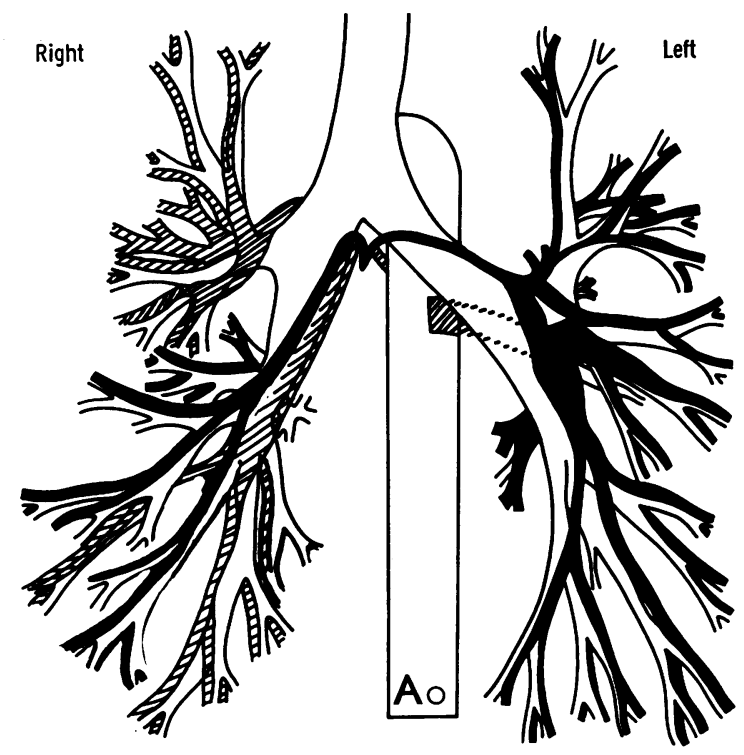

Fig. 1 Pulmonary arterial branching pattern in case 5. The solid lines indicate the central pulmonary arteries and their branches, and the cross-hatched lines indicate collateral arteries and the intrapulmonary arteries with which they connect. In the right lung, the central pulmonary arteries only connect with the middle lobe and two segments of the lower lobe. Ao, aorta.

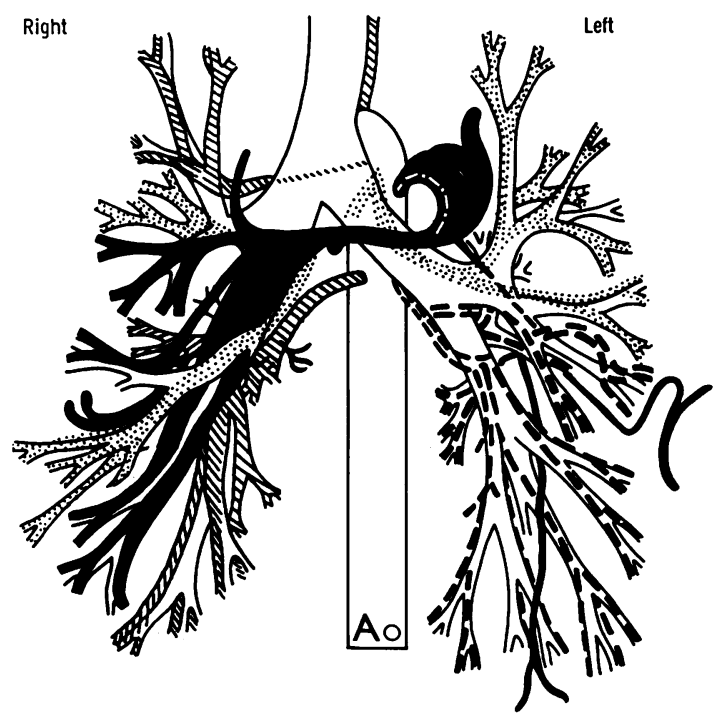

Fig. 2 Pulmonary arterial branching pattern in case 4. The solid lines indicate the central pulmonary arteries and their branches, and the cross-hatched, stippled, interrupted, and dotted lines, the collateral arteries and the intrapulmonary arteries with which they connect. Ao, aorta. 
the centrally connected pulmonary artery. Collaterals to a lower lobe pulmonary artery ran posterior to the lower lobe bronchus, anastomosing at its lateral margin. Of the collateral arteries not connecting with the central or lobar pulmonary arteries, those vessels supplying segments of the upper and lower lobe usually ran posterior to the appropriate bronchus, save those to the anterior basal segment of both lower lobes and the median basal segment of the right lower lobe, which ran along the inferior margin of the main or lower lobe bronchi before entering the lung. On entering the lung, all these vessels ran towards the nearest lobar or segmental airway, coming to lie in the normal position of a "true" normally connected pulmonary artery, anterolateral to the airway. Macroscopical dissection, until at least one division beyond segmental level, showed that these vessels branched with the airways (Fig. 1 and 2). Microscopically, in the serial sections of injected material the intrapulmonary vessels which connected to each segmental artery continued to branch with the airways, the small bronchioli, terminal and respiratory bronchioli, and alveolar ducts until they reached the capillary bed of the alveolar wall.

Considering the group as a whole, the central pulmonary arteries were only connected to $93 / 209$ bronchopulmonary segments whereas the collateral arteries were the only arteries connected to a further $91 / 209$. In an additional 19 segments both centrally connected and collateral arteries accompanied lobar and segmental airways, but further along the pathway the arteries diverged, each accompanying a different airway to supply a different portion of the bronchopulmonary segment. The remaining six segments were perfused by an artery running alongside the trachea. Five of these segments were within an upper lobe and the remaining segment within a middle lobe.

The bronchial arteries entered four lobes which were perfused by collateral arteries. The remaining identified bronchial arteries perfused regions of lung connected to central pulmonary arteries. Enlargement of the bronchial arteries occurred in two cases, involving three lobes where the central pulmonary arteries were extremely small. In one injected case (case 4), a collateral artery arising from underneath the aortic arch gave rise to a small branch which ran into the wall of the right lower lobe posterobasal bronchus.

Dissection and tracing of all arteries entering the lung failed to show any macroscopical connections distal to the lobar bronchi between arteries connected to the central pulmonary arteries and those arising from the aorta. On microscopical examination of all lung sections, including the serial sections, no anastomoses were seen between peripheral pulmonary arteries connected to central and collateral arteries.

\section{SIZE OF PULMONARY ARTERIES}

The main, right, and left pulmonary arteries were extremely small, but were patent in all except case 8 (Table 2). The central pulmonary arteries were particularly small where they had been perfused by retrograde flow from a collateral vessel which anastomosed with the lower lobe artery (cases 5, 8, and 9). Within the lung the arteries were usually abnormally small, whatever the type of proximal connection (Table 2). In the right lower lobe, for example, an approximately equal number of segments were connected to collateral and central pulmonary arteries in $8 / 11$ cases. Nearly all the lower lobe arteries were small in relation to the size of the airway, 12 measuring less than $3 \mathrm{~mm}$ in diameter. In the three remaining specimens all the segments of the right lower lobe were supplied by a single artery and even then, in two instances, the vessel measured only $2.5 \mathrm{~mm}$ in diameter. In five specimens the arteries connected to a collateral vessel were larger than those connected to the central pulmonary artery (Table 2).

The effect of an aortopulmonary anastomosis in an individual patient cannot obviously be judged from a study of postmortem material. Arterial size was not, however, noticeably greater in treated than in untreated specimens. After an aortocollateral anastomosis (case 6), the intrapulmonary artery connected to the collateral remained small, measuring $2 \mathrm{~mm}$.

The pulmonary arteries, though small, had a normal appearance, save in cases 9 and 12, where the normally connected left and right upper lobe

Table 2 Pulmonary arterial size: external diameter ( $\mathrm{mm}$ )

\begin{tabular}{|c|c|c|c|c|}
\hline \multirow{2}{*}{$\begin{array}{l}\text { Case } \\
\text { no. }\end{array}$} & \multicolumn{2}{|c|}{ Central pulmonary arteries } & \multicolumn{2}{|c|}{$\begin{array}{l}\text { Intrapulmonary arteries of } \\
\text { right lower lobe, connected to }\end{array}$} \\
\hline & Right & Left & Pulmonary valve & Aorta \\
\hline $\begin{array}{l}1 \\
2 \\
3 \\
4^{\star} \\
5 \\
6 \\
7 \\
8 \\
9 \\
10 \\
11^{\star}\end{array}$ & $\begin{array}{l}3 \\
5 \\
5 \\
4 \cdot 2 \text { (APA) } \\
2 \cdot 8 \\
\text { Pp (APA) } \\
2 \cdot 5 \\
\text { Not pp } \\
2 \cdot 3 \\
4 \cdot 5 \\
8\end{array}$ & $\begin{array}{l}2 \cdot 5 \\
4 \\
5 \\
3 \\
2 \cdot 8 \\
\text { Pp } \\
2 \cdot 5 \\
\text { Not pp } \\
2 \\
4 \cdot 5 \\
7\end{array}$ & $\begin{array}{l}2 \cdot 5 \\
1 \cdot 5 \\
4 \\
4 \\
2 \cdot 8 \\
1 \cdot 5 \\
2 \cdot 2 \\
2 \cdot 5 \\
7 \cdot 5 \\
5 \cdot 1\end{array}$ & $\begin{array}{l}2 \cdot 8 \\
2 \cdot 3 \\
2 \cdot 5 \\
3 \\
2 \\
3 \cdot 5 \\
2 \cdot 5 \\
6 \cdot 5 \\
- \\
\overline{2 \cdot}\end{array}$ \\
\hline
\end{tabular}

All measurements made on fixed material.

$\star$ Arteries distended by injection.

APA, aortopulmonary anastomosis; pp, probe patent. 
pulmonary arteries, respectively, were dilated and saccular at lobar and segmental level.

\section{STENOSES}

Dissection of the uninjected specimens showed at least one site of narrowing in 20/36 collateral arteries. A narrowed segment between the aorta and the lung was the commonest site of stenosis, present in 15 collaterals. A localised constriction occurred at the aortic origin of four collaterals and at the anastomosis of a collateral with the normally connected extrapulmonary or lobar pulmonary artery in four of the nine cases with this type of connection. In the two injected specimens, macroscopical and radiological examination of the 12 collateral arteries present demonstrated five examples of segmental narrowing of a collateral artery, two examples of a localised stenosis of a collateral at its aortic origin, and two of narrowing at the anastomosis of a collateral with a lobar pulmonary artery. Radiologically, no stenoses were seen at segmental level or beyond.

In all cases, when a collateral reached a bronchus either at the hilum or within the lung, the vessel increased considerably in size and became thin walled immediately before it branched with the airways and followed the course of a normally connected pulmonary artery.

\section{MICROSCOPICAL STUDIES}

In all cases, when a collateral artery arose from the aorta the wall structure resembled that of a muscular systemic artery. Within the lung, all the collaterals examined connected with vessels which had the structure of a normal pulmonary artery with a thin media containing six to eight elastic laminae between internal and external elastic laminae. The detailed histological studies of collateral arterial structure are presented elsewhere. ${ }^{6}$

Within the lung, in all cases the alveolar walls appeared normal, but the thickness of connective tissue septa was frequently increased.

\section{Arterial wall structure}

Percentage medial thickness was similar in segments of lung perfused by centrally connected pulmonary arteries and by collaterals in the five cases in which the comparison was made, and was either normal or reduced (Fig. 3). Examination of the structure of arteries accompanying peripheral airways showed that muscle extended as far along the arterial pathway as is normal for age, save in the oldest child, case 11, where muscle failed to extend as far along the pathway as normal. In three cases, a total of four segments contained vessels showing eccentric intimal change which encroached little on the arterial lumen. These findings are usually associated with a low pulmonary blood flow. In the older 3-year-old child, many small preacinar arteries and arteries accompanying terminal and respiratory bronchioli in the median basal segment of the right lung showed concentric intimal fibrosis, with partial or complete obliteration of the lumen. In this segment of lung, postmortem arteriography showed a reduction in density of the background haze, suggesting a reduction in number of intra-acinar arteries.?

Of the remaining three cases in which no comparison was made between segments perfused by collateral and centrally connected pulmonary arteries, each contained at least one segment showing the medial hypertrophy and abnormal extension of muscle along the arterial pathway associated with pulmonary hypertension. Two segments were connected to a centrally connected pulmonary artery fed by a large collateral vessel, and one to a large collateral artery. Only two segments showed, in addition to medial hypertrophy, concentric intimal proliferation. One segment was perfused by a Blalock-Taussig shunt

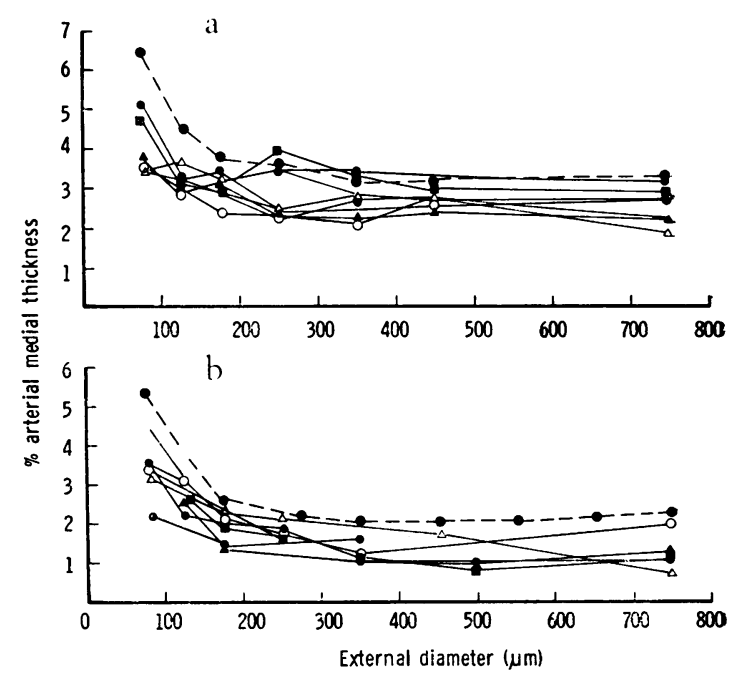

Fig. 3 Pulmonary arterial medial thickness related to external diameter ( $\mu m$ ); (a) case 4, aged 1.5 months, illustrating muscularity in three bronchopulmonary segments of the right and four segments of the left lung (solid lines), compared with normal (interrupted line); (b) case 11, aged 3 years, illustrating muscularity in five segments of the right and two segments of the left lung (solid lines), compared with normal of similar age (interrupted line). In each case, muscularity is generally below normal and similar in different segments of lung, each segment being perfused by a different vessel. 
and the other by a large collateral perfusing only two segments of lung.

Thus, in a majority of cases the microscopical findings in all sections of lung examined were compatible with a reduction in pulmonary blood flow. In only three cases was there structural evidence of pulmonary hypertension.

\section{Peripheral arterial size}

Arterial size varied between and within cases. In five cases, the arteries accompanying respiratory bronchioli were abnormally small in some or all of the segments examined. In the four remaining cases arterial size was normal in all segments examined.

In general, the size of arteries accompanying peripheral airways was related to the size of the perfusing vessel and showed greater variation within each case than did arterial muscularity. In the two injected specimens precise measurements of external diameter were made at all levels along the arterial pathway. In case 4, the intra-acinar arteries of the right lung supplied by normally connected pulmonary arteries into which a Goretex shunt had been inserted were of normal size (Fig. 4). By contrast, in three of the four segments perfused by different collateral arteries, the vessels were smaller than is found in the normal child at birth. The smallest arteries were seen in the right lower lobe perfused initially by collateral arteries which had been ligated at 18 days of age. In case 11 , the intra-acinar arteries from the level of the terminal bronchioli to the alveolar walls were smaller at 3 years of age than in the normal lung at 6 months in all the five segments examined (Fig. 4).

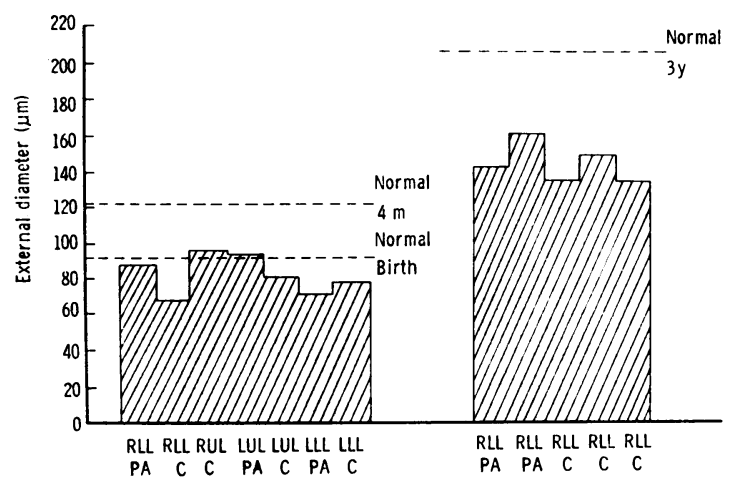

Fig. 4 External diameter $(\mu m)$ of arteries accompanying respiratory bronchioli in bronchopulmonary segments perfused either via central pulmonary arteries (PA) or collaterals (C), in case 4 on the left, and case 11 on the right. Both cases show a reduction in arterial size in nearly all segments of lung examined, as compared with findings in children of similar age.

\section{Arterial number}

In both injected cases alveoli and arterial number per unit area was normal. In case 4 , the alveolar/ arterial ratio varied between 9.37 and 11.5 in six segments and in case 11 , between 9.0 and 12.2 in the five segments examined.

\section{Discussion}

This is the first detailed study of the anatomy of the pulmonary circulation in pulmonary atresia with major aortopulmonary collateral arteries. Examination of 11 necropsy specimens showed, in all cases, central pulmonary arteries which had generally been perfused retrogradely by collateral arteries anastomosing with the lobar pulmonary arteries or, less commonly, with the pulmonary arteries at the hilum. Considering the group as a whole, normally connected pulmonary arteries perfused approximately half the bronchopulmonary segments. The remaining segmental arteries were connected to collateral arteries, which within the lung had the structure of normally connected pulmonary arteries and branched with the pre- and intra-acinar airways in the normal manner to perfuse the alveolar-capillary bed. Occasionally two intrapulmonary arteries, one connected to a central pulmonary artery and one to a collateral, accompanied a lobar or segmental bronchus, but after further airway division, the arteries diverged to accompany different airways. The segmental pulmonary arteries were generally abnormally small in relation to the size of the accompanying airway, irrespective of the type of proximal connection. Stenoses occurred in the majority of collateral arteries often as a thick narrowed segment between the aorta and lung.

Microscopically, the structural changes at the lung periphery were consistent with reduction in pulmonary blood flow in five of the nine cases examined, irrespective of the type of proximal connection. In three cases, medial hypertrophy suggested the presence of pulmonary hypertension. The peripheral pulmonary circulation had failed to grow normally in all save the patient who died at 12 days of age.

EMBRYOLOGY AND NOMENCLATURE

Major aortopulmonary collateral arteries have been variously called "bronchial arteries", "systemic arteries", and "persistent segmental arteries". The purely descriptive term major aortopulmonary collateral arteries has also been eschewed by some authors because in their series the vessels did not always originate from the aorta. ${ }^{8}$ In the present study, however, nearly all the collateral arteries 
were seen to arise from the aorta. In addition, in eight cases bronchial arteries were seen to arise as a distinctly separate system from the tracheobronchial plexus around the carina and were distributed to the large airways in a normal manner. Four lobes containing bronchial arteries were perfused by collateral arteries arising from the descending thoracic aorta. Recent embryological studies by Boyden ${ }^{910}$ suggest that major aortopulmonary collateral arteries are persistent segmental arteries, not bronchial arteries. The present study supports this hypothesis. During early fetal development the vascular plexus forming in the lung buds is connected to segmental arteries arising from the dorsal aortae. Within the lung, by the 40th day, the vascular plexus has differentiated into definitive segmental arteries and their branches, ${ }^{11}$ and the lung is perfused both by the right ventricle and sixth branchial arches and by segmental arteries, until the latter disappear about 50 days after ovulation. Findings in the present study suggest that during this time some bronchopulmonary segments or lobules are connected to the right ventricle and others to the aorta. In the normal fetus, as the lung develops it becomes entirely and exclusively supplied by central pulmonary arteries derived from the sixth branchial arches. In pulmonary atresia with ventricular septal defect, however, it appears that the normal maturation process is arrested.

Nearly all the collateral arteries in the present series arose from the same region of the midthoracic aorta. Hessel et al. ${ }^{12}$ considered that such arteries must have arisen in utero above the zone from which segmental arteries normally descend from the "neck" region of the embryo to below the diaphragm. These observations suggest that in the present series, normal fetal development was interrupted at about the same age in all cases. Furthermore, the primary abnormality appears to lie in the heart, and sixth branchial arches. The lung segment appears to have developed normally, as regards both arteries and airways, any structural change being the result of abnormalities in blood pressure and flow. None of the lung tissue in the present series was sequestrated, airway development being normal. Boyden ${ }^{2}$ emphasised that collateral arteries developed early and bronchial arteries late, long after the blood supply to the lung is established. He described a $41 \mathrm{~mm}$ embryo in which the right posterobasal segment of lung was perfused by an aortic branch at a time when the origin of the bronchial arteries could be seen, but no vessels yet reached the root of the lung. In the present study bronchial arteries could be differentiated from major aortopulmonary collateral arteries because they were smaller and their origin could be traced to the vascular plexus around the carina and lower end of the trachea. Bronchial arteries probably enlarge because the centrally connected pulmonary arteries are, or become, extremely small. In three cases, arteries running down the lateral margin of the trachea entered the upper lobes, branched with the airways, and appeared to be the only blood supply to certain segments. The origin of these vessels is unknown.

\section{COMPARISON OF PRESENT FINDINGS WITH}

\section{PREVIOUS CLINICAL STUDIES}

The first report of some segments of lung being perfused by central pulmonary arteries and others solely by a systemic artery is probably that of Joseph Hyrtle, published in 1839, in a child who did not have congenital heart disease. ${ }^{12}$ More recently, radiological studies showed that this occurs in pulmonary atresia with ventricular septal defect. ${ }^{13-15}$ The present study extends these observations by showing that the intrapulmonary arteries with which the collaterals connect are "true" pulmonary arteries, that not only the segments, but the subsegments of a lobe may have a different proximal connection, and that the proportion of a lung directly connected to a collateral artery can vary from 0 to nearly 100 per cent.

In this necropsy study central pulmonary arteries were present in all cases, perfused by major aortopulmonary collateral arteries joining a lobar or, less commonly, an extrapulmonary vessel. Theoretically, therefore, selective angiography of all collateral arteries would have shown central pulmonary arteries in all but one patient in whom the vessels were not patent. In practice, selective angiography usually does demonstrate central pulmonary arteries, but most authors note the exceptional case. ${ }^{81617}$

In life, assessment of the adequacy of central pulmonary arteries for insertion either of a prosthetic shunt or a valve-bearing conduit is difficult. In the present study, the central pulmonary arteries were obviously small. Had they been distended before fixation they would still have been small relative to the size of the accompanying airway. Probably in only two cases, however, would the vessels have been too hypoplastic to take a prosthetic shunt. In a recent radiological study, the central pulmonary arteries were considered hypoplastic in relation to the size of the aortic root and vertebral bodies in 48 per cent of cases, but severe hypoplasia was not thought to contraindicate surgical treatment. ${ }^{15}$ Findings in the present study suggest that even when the central pulmonary 
arteries are severely hypoplastic it may be possible to shunt to a larger hilar pulmonary artery.

The site of origin of the collateral arteries, and their extra- and intrapulmonary course was more constant in this than in other series, ${ }^{815}$ and might be a result of the relatively small number of cases studied. There was, however, considerable variation between cases in the number of collateral arteries arising from the aorta, the number of branches arising from each collateral, and the number of bronchopulmonary segments connected to collateral arteries. Not surprisingly, in a necropsy study, the number of collaterals in each case tended to be greater than in previous radiological studies. ${ }^{815}$ This observation is important because failure to show central pulmonary arteries is usually because of failure to appreciate the number of collaterals available for selective angiography, as many as six per case in this series. In addition, failure to identify all collaterals leads to an overestimation of the proportion of lung connected to central pulmonary arteries.

\section{STENOSES}

Stenoses of major aortopulmonary collateral arteries were first noted angiocardiographically by Jefferson et al..$^{13}$ and pressure gradients across them were documented the following year. ${ }^{18} \mathrm{~A}$ stenosis can occur at the origin of a collateral from the aorta, along its course, and where it anastomoses with a pulmonary artery. Each collateral may have more than one stenosis. In a recent radiological study 42 per cent of all collateral arteries arising from the aorta were stenosed, affecting 70 per cent of patients. ${ }^{15}$ In the present series a higher proportion $(58.8 \%)$ of collaterals was stenosed and all patients had at least one stenosed vessel. In the radiological series, stenoses occurred most frequently at the junction of a collateral with a hilar pulmonary artery, and were present in 47 per cent of patients. In the present series a similar proportion of cases, 55 per cent, had this type of stenosis, but a narrowed segment occurred in all cases and accounted for 76 per cent of all stenoses.

Despite the incidence of stenosis being higher in this than in previous studies the incidence was probably underestimated. In nine of the 11 cases the arteries were not distended by injection and though all collaterals were examined carefully macroscopically, only 13 were examined microscopically by step or serial sections. In addition, in the two injected cases radiological assessment yielded a disproportionately greater number of stenosed collateral arteries than in the uninjected material.

Occasionally the lumen of a collateral was occluded, because of the fusion of intimal mounds or cushions in a long narrow segment. Obviously, when this happens the distal patent segment of a collateral artery anastomosing with a very small, but structurally normal intrapulmonary artery, cannot be shown radiologically, except, perhaps, by pulmonary vein angiography. 19

When planning either to shunt to a region of lung perfused by a collateral artery or to connect such a portion of lung to the sixth arch it is necessary to check for the presence of stenoses both by intravascular pressure measurement, by angiography, and by palpation of the vessel at operation. The latter is helpful in detecting a thick-walled, narrowed segment. In life, the radiographic appearance of the vessels is unreliable in assessing the haemodynamic state. Macartney et al. ${ }^{14}$ found a pressure gradient of $60 \mathrm{~mm}$ or more in vessels in which angiography had failed to reveal a stenosis.

Stenoses of the intrapulmonary arteries were not seen in the present series. Though they could have been overlooked in fixed undistended material, they were not shown either macroscopically or radiologically in the two injected cases.

\section{STRUCTURE OF INTRAPULMONARY ARTERIAL} CIRCULATION

Preacinar arteries

The preacinar arteries, both those connected to collateral arteries and those connected to central pulmonary arteries, were generally abnormally small, both absolutely and in relation to the size of the accompanying airway. Three children had had a surgical aortopulmonary or aortocollateral anastomosis created. After an aortopulmonary anastomosis in two, the distal lobar pulmonary artery appeared larger than in the untreated cases and was normal relative to the size of the accompanying airway. Unfortunately, however, in both cases the distal vessel perfused only five bronchopulmonary segments or less, and in one child the dilated lobar and segmental arteries severely compressed the right middle lobe and lower lobe bronchi. In the other patient a large aortopulmonary anastomosis failed to perfuse the contralateral lung because the central pulmonary arteries were barely probe patent. These findings emphasise the necessity of careful preoperative evaluation by selective angiography.

In two cases one lobar pulmonary artery and its segmental branches showed saccular dilatation. This appearance is seen not infrequently during life after a successful aortopulmonary anastomosis (personal observation). Its presence in two untreated cases indicates that such dilatation can occur as a primary abnormality of the vessel wall in pulmonary atresia with ventricular septal defect and major 
aortopulmonary collateral arteries, and is not necessarily a result of an increase in pulmonary blood flow.

\section{Intra-acinar arteries}

In the normal child most of the intra-acinar arteries develop after birth, during the first three years of life." The haemodynamic abnormalities produced by a variety of different types of congenital heart disease are known to impair the normal development of these vessels. ${ }^{20-92}$ The present study shows that pulmonary atresia with ventricular septal defect and major aortopulmonary collateral arteries is no exception.

Peripheral pulmonary vascular structure determines resistance and hence operability, but this is the first time that vessel growth has been assessed in this condition where different segments of lung frequently have a different blood supply. Greater accuracy is achieved by studying injected rather than uninjected material, but examination of both types of tissue gave similar results. Within each case arterial muscularity, size, and number were surprisingly similar in segments of lung perfused by normally connected pulmonary arteries and by collaterals. This probably occurred because the majority of segments were underperfused and because most of the patients were infants, the lung having been exposed to abnormalities of pressure or flow for a relatively short period of time. Case 11 illustrates the variation in pulmonary vascular structure which can develop by 3 years of age, even within a segment of lung perfused by a single vessel. Abnormally thin-walled arteries lay adjacent to others showing concentric intimal proliferation, probably resulting from organisation of thrombus.

Most cases showed normal or reduced pulmonary arterial medial thickness and external diameter and, in three cases, the vessels contained areas of eccentric intimal proliferation. All these structural changes are compatible with a reduction of pulmonary blood flow. ${ }^{23-25}$ In at least two cases, however, any reduction in flow or pressure was not sufficient to impair arterial multiplication.

Structural evidence of pulmonary hypertension was found in only three cases and was not severe. The only case to show early intimal proliferation had had a Blalock-Taussig shunt to one region and a larger collateral supplying another region of lung examined. Previous studies have emphasised the danger of large collateral arteries without a protective stenosis perfusing the pulmonary vascular bed at high pressure and causing obliterative pulmonary vascular disease. ${ }^{13} 14$ The prevalence of pulmonary hypertensive change probably depends on the age of the patients in each series. Patients who live longer presumably have larger collateral arteries and a higher pulmonary blood flow than in the present series, making them susceptible to obliterative change.

The present study indicates that though stenoses in the collateral arteries "protect" the pulmonary vascular bed from developing hypertensive pulmonary vascular change they may also prevent the lung from being adequately perfused, causing failure of the intra-acinar pulmonary circulation to develop normally. Such a lung may not be capable of accepting an increase in blood volume, as after an aortopulmonary anastomosis or insertion of a right ventricular conduit, without an increase in resistance. In infants with a large ventricular septal defect an increase in resistance is associated first with failure of the peripheral pulmonary circulation to grow normally, before obliterative pulmonary vascular disease develops. ${ }^{22}$

\section{CLINICAL IMPLICATIONS}

Findings in the present study are helpful in understanding the natural history of pulmonary atresia with ventricular septal defect and major aortopulmonary collateral arteries. The rapid increase in cyanosis frequently seen during the first weeks of life is often attributed to closure of the ductus arteriosus, but the role of the ductus in this condition depends on the proportion of lung connected to the central pulmonary arteries. Increasing cyanosis may also be a result of progressive stenosis of the collateral arteries. In older children the picture is more complex. Increasing cyanosis may be a result either of failure of the collateral to increase in size with growth of the child, particularly in stenosed regions, of failure of the intrapulmonary arterial circulation to grow normally, or of thrombus formation in some peripheral arteries and obliterative pulmonary vascular disease in others. In any child the clinical findings and total pulmonary vascular resistance are the sum of the changes taking place in each segment of lung tissue.

The anatomical findings are so variable in pulmonary atresia with ventricular septal defect and major aortopulmonary collateral arteries that all cases must be considered individually. In order to plan effective treatment a cardiac catheterisation study is advisable at the first hospital admission. If possible, all the collateral arteries should be catheterised in order to demonstrate the central pulmonary arteries and the proportion of lung connected to them. Ideally, the blood supply of each bronchopulmonary segment should be visualised and the intrapulmonary arterial pressure measured. 
Correction of the abnormality is usually undertaken as a two-stage procedure. The aim of the firststage operation is to increase pulmonary blood flow in order to allow the child to thrive and to encourage the pulmonary circulation to grow and develop normally. An aortopulmonary shunt is inserted, if possible, into a centrally connected pulmonary artery which is known to perfuse the majority of bronchopulmonary segments of one lung and to be connected through a good lumen with the contralateral lung. Any shunt into a collateral vessel should be performed distal to any stenosis, that is, into the thin-walled elastic pulmonary artery beyond the collateral. This should ensure that the blood supply will not be prejudiced by any further occlusive change in the collateral vessel. Before correcting the abnormality by connecting the pulmonary arterial circulation to a right ventricular conduit as many bronchopulmonary segments as possible should be connected to the main perfusing vessel, hopefully a central pulmonary artery or one of its major branches. Postoperatively, in tetralogy of Fallot with pulmonary atresia the mortality is greater, and the right ventricular pressure is higher, in patients with large collateral arteries than in those without them and the postoperative right ventricular/left ventricular pressure ratio, itself a strong predictor of operative survival, is much increased in the presence of "arborisation abnormalities" particularly when these are bilateral. ${ }^{26}$ Since "arborisation abnormalities" presumably indicate the presence of collaterals not connected to central pulmonary arteries, bilateral arborisation abnormalities were present in nearly all the patients we studied.

Ideally, collateral arteries supplying a substantial volume of the pulmonary vascular bed should be reconnected and not ligated. Ligation of an isolated collateral is effectively ligation of an intrapulmonary artery which is known to produce hypertrophy of the bronchial arterial circulation.27 Gas exchange can occur in such a lung, but the normal architecture of the intrapulmonary arterial circulation is permanently destroyed. However, ligation of such a collateral may be preferable to leaving it unligated if it cannot be connected directly or indirectly to central pulmonary arteries. The rationale for this is that interruption of one pulmonary artery causes hypoplasia of the ipsilateral lung and enlargement of the contralateral lung. ${ }^{28}$ Thus bronchopulmonary segments connected to pulmonary arteries may come to compose a greater proportion of the entire lung issue than they would have done had not the isolated major aortopulmonary collateral artery or arteries been ligated.

After corrective surgery a rise in right ventricular pressure might be the result of any one or more of the following features: (a) failure of the right ventricle to perfuse the majority of bronchopulmonary segments; (b) proximal or distal pulmonary artery stenosis; (c) failure of the central and peripheral pulmonary arterial circulation to grow and develop normally; and (d) obliteration of pulmonary vessels, either secondary to hypoperfusion or to pulmonary hypertension.

This paper provides a rational basis for treatment, but the practical difficulties encountered in investigating and treating these patients will doubtless prevent total correction in many cases. In the fortunate child, however, at a second stage operation the right ventricle would be connected to lowpressure central pulmonary arteries perfusing the majority of bronchopulmonary segments.

\section{References}

1 Davies G, Reid L. Growth of the alveoli and pulmonary arteries in childhood. Thorax 1970; 25: 669-81.

2 Hislop A, Reid L. New pathological findings in emphysema of childhood: 1. Polyalveolar lobe with emphysema. Thorax 1970; 25: 682-90.

3 Foster-Clark AF. Chest diseases. vol 1. London: Butterworths, 1963: 19, 21-2.

4 Hislop A, Reid L. Pulmonary arterial development during childhood: branching pattern and structure. Thorax 1973; 28: 129-35.

5 Rabinovitch M, Haworth SG, Castaneda AR, Nadas AS, Reid LM. Lung biopsy in congenital heart disease: a morphometric approach to pulmonary vascular disease. Circulation 1978; 58: 1107-22.

6 Haworth SG. Collateral arteries in pulmonary atresia with ventricular septal defect: a precarious blood supply. Br Heart $\mathcal{F} 1980 ; 44$ : 5-13.

7 Anderson EG, Simon G, Reid L. Primary and thrombo-embolic pulmonary hypertension: a quantitive pathological study. F Pathol 1973; 110: 273-93.

8 McGoon DC, Baird DK, Davis GD. Surgical management of large bronchial collateral arteries with pulmonary stenosis or atresia. Circulation 1975; 52: 109-18.

9 Boyden EA. The time lag in the development of bronchial arteries. Anat Rec 1970; 166: 611-4.

10 Boyden EA. The developing bronchial arteries in a fetus of the twelfth week. Am $\mathcal{F}$ Anat 1970; 129: 357-68.

11 Wells LJ, Boyden EA. The development of the bronchopulmonary segments in human embryos of Horizons XVII to XIX. Am f Anat 1954; 95: 163201.

12 Hessel EA, Boyden EA, Stamm SJ, Sauvage LR. High systemic origin of the sole artery to the basal segments of the left lung: findings, surgical treatment and embryologic interpretation. Surgery 1970; 67: 624-32. 
13 Jefferson K, Rees S, Somerville J. Systemic arterial supply to the lungs in pulmonary atresia and its relation to pulmonary artery development. $\mathrm{Br}$ Heart f 1972; 34: 418-27.

14 Macartney FJ, Scott O, Deverall PB. Haemodynamic and anatomical characteristics of pulmonary blood supply in pulmonary atresia with ventricular septal defect-including a case of persistent fifth aortic arch. Br Heart F 1974; 36: 1049-61.

15 McGoon MD, Fulton RE, Davis GD, Ritter DG, Neill CA, White RI Jr. Systemic collateral and pulmonary artery stenosis in patients with congenital pulmonary valve atresia and ventricular septal defect. Circulation 1977; 56: 473-9.

16 Chesler E, Beck W, Schrire V. Selective catheterization of pulmonary or bronchial arteries in the preoperative assessment of pseudotruncus arteriosus and truncus arteriosus type IV. Am $\mathcal{F}$ Cardiol 1970; 26: 20-4.

17 Berry BE, McGoon DC, Ritter DG, Davis GD. Absence of anatomic origin from heart of pulmonary arterial supply: clinical application of classification. f Thorac Cardiovasc Surg 1974; 68: 119-25.

18 Macartney F, Deverall P, Scott O. Haemodynamic characteristics of systemic arterial blood supply to the lungs. Br Heart $\mathcal{F}$ 1973; 35: 28-37.

19 Singh SP, Rigby ML, Astley R. Demonstration of pulmonary arteries by contrast injection into pulmonary vein. $B r$ Heart $\mathcal{F} 1978$; 40: 55-57.

20 Haworth SG, Reid L. Quantitative structural study of pulmonary circulation in the newborn with pulmonary atresia. Thorax 1977; 32: 129-33.

21 Haworth SG, Reid L. A structural study of the pulmonary circulation and of the heart in total anomalous pulmonary venous return in early infancy. Br Heart f 1977; 39: 80-92.

22 Haworth SG, Sauer U, Bühlmeyer K, Reid L. The development of the pulmonary circulation in ventricular septal defect: a quantitative structural study. Am $\mathcal{F}$ Cardiol 1977; 40: 781-8.

23 Civin WH, Edwards JE. Pathology of the pulmonary vascular tree. I. A comparison of the intra-pulmonary arteries in the Eisenmenger syndrome and in stenoses of ostium infundibuli associated with biventricular origin of the aorta. Circulation 1950; 2: 545-52.

24 Best PV, Heath D. Pulmonary thrombosis in cyanotic congenital heart disease without pulmonary hypertension. F Pathol Bacteriol 1958; 75: 281-91.

25 Naeye RL. Perinatal changes in the pulmonary vascular bed with stenosis and atresia of the pulmonic valve. Am Heart f 1961 ; 61 : 586-92.

26 Alfieri O, Blackstone EH, Kirklin JW, Pacifico AD, Bargeron LM Jr. Surgical treatment of tetralogy of Fallot with pulmonary atresia. $\mathcal{f}$ Thorac Cardiovasc Surgery 1978; 76: 321-35.

27 Liebow AA, Hales MR, Bloomer WE, Harrison W, Lindskog GE. Studies on the lung after ligation of the pulmonary artery. II. Anatomical changes. $\mathrm{Am}$ f Pathol 1950; 26 : 177-95.

28 Pool PE, Vogel JHK, Blount SG. Congenital unilateral absence of a pulmonary artery. The importance of flow in pulmonary hypertension. $\mathrm{Am}$ f Cardiol 1962; 10: 706-32.

Requests for reprints to Dr S G Haworth, Department of Paediatric Cardiology, The Hospital for Sick Children, Great Ormond Street, London WC1N 3JH. 